\title{
Physical activity and sleep duration during pregnancy have interactive effects on caesarean delivery: a population-based cohort study in Tianjin, China
}

Yingzi Yang ${ }^{1+}$, Weiqin $\mathrm{Li}^{2+}$, Wen Yang ${ }^{1}$, Leishen Wang${ }^{2}$, Jinnan Liu' ${ }^{1}$ Junhong Leng ${ }^{3}$, Wei Li ${ }^{2}$, Shuo Wang ${ }^{2}$, Jing Li ${ }^{1}$, Gang $\mathrm{Hu}^{4}$, Zhijie $\mathrm{Yu}^{5}$ and Xilin Yang ${ }^{1,6,7^{*}}$

\begin{abstract}
Background: There were inconsistent findings in the literature regarding the associations of physical activity and sleep duration during pregnancy with caesarean delivery for different reasons. It was also unknown whether physical activity and sleep duration during pregnancy had interactive effects on the risks of different types of caesarean delivery. The study aimed to investigate the effects of physical activity, sleep duration and their interactions on the risk of caesarean delivery for medical reasons and non-medical reasons.

Methods: From October 2010 to August 2012, a prospective population-based cohort of 13,015 pregnant women was established in six central urban districts of Tianjin, China. Pregnancy outcomes were retrieved from an electronic database and caesarean delivery was divided into caesarean delivery for medical reasons and caesarean delivery for non-medical reasons. Physical activity and sleep status were collected at 24-28 weeks of gestation using self-reported questionnaires. Logistic regression and additive interaction were used to examine physical activity, sleep duration and their interactive effects on risk of caesarean delivery.

Results: In the cohort, 5692 (43.7\%) and 2641 (20.3\%) of women had caesarean delivery for medical reasons and non-medical reasons, respectively. Low physical activity increased the risk of caesarean delivery for medical reasons (adjusted OR: 1.13, 95\%Cl 1.04-1.23) but not caesarean delivery for non-medical reasons. Sleep duration $<7$ h/day and poor sleep quality were not associated with caesarean delivery. Sleep duration $\geq 9 \mathrm{~h} /$ day increased the risk of caesarean delivery for medical reasons $(1.12,1.02-1.22)$ and caesarean delivery for non-medical reasons $(1.16,1.05-$ 1.29). Co-presence of low physical activity and sleep duration $\geq 9 \mathrm{~h} /$ day increased risk of caesarean delivery $(1.25$, 1.12-1.41), and their additive interaction was statistically significant for caesarean delivery for medical reasons but not for caesarean delivery for non-medical reasons.

(Continued on next page)
\end{abstract}

\footnotetext{
* Correspondence: yxl@hotmail.com; yangxilin@tmu.edu.cn

${ }^{\dagger}$ Yingzi Yang and Weiqin Li contributed equally to this work.

'Department of Epidemiology and Biostatistics, School of Public Health,

Tianjin Medical University, P.O. Box 154, 22 Qixiangtai Road, Heping District,

Tianjin 300070, China

Full list of author information is available at the end of the article
}

(C) The Author(s). 2021 Open Access This article is licensed under a Creative Commons Attribution 4.0 International License, which permits use, sharing, adaptation, distribution and reproduction in any medium or format, as long as you give appropriate credit to the original author(s) and the source, provide a link to the Creative Commons licence, and indicate if changes were made. The images or other third party material in this article are included in the article's Creative Commons licence, unless indicated otherwise in a credit line to the material. If material is not included in the article's Creative Commons licence and your intended use is not permitted by statutory regulation or exceeds the permitted use, you will need to obtain permission directly from the copyright holder. To view a copy of this licence, visit http://creativecommons.org/licenses/by/4.0/. The Creative Commons Public Domain Dedication waiver (http://creativecommons.org/publicdomain/zero/1.0/) applies to the data made available in this article, unless otherwise stated in a credit line to the data. 
(Continued from previous page)

Conclusions: Low physical activity and excessive sleep duration during pregnancy each increased the risk of caesarean delivery, and they had an interactive effect on the risk of caesarean delivery for medical reasons but not on the risk of caesarean delivery for non-medical reasons. Increasing physical activity and maintaining recommended sleep duration during pregnancy may have benefits for perinatal health.

Keywords: Physical activity, Sleep duration, Caesarean delivery, Pregnancy, Chinese

\section{Background}

Globally, caesarean delivery $(\mathrm{CD})$ rate had doubled to $21.1 \%$ in the past 15 years and increased annually by $4 \%$ $[1,2]$. China had the highest rate of CD in the world and the rate was also on the rise in the past decades, increased from $46.2 \%$ in 2004 to $47.6 \%$ in 2011 [3]. The underlying reasons were multifaceted, including policy, clinical decisions, socioeconomic status and psychological state of pregnant women $[4,5]$. CD was performed with or without medical indications in clinical practice and had short-term and long-term health consequences such as maternal mortality and neonatal physiology alteration, especially when carried out without medical indications [6]. Thus, curbing the undue increase of CD rate in China has become a critical problem that needs to be solved [7].

Physical activity (PA) was a well-established factor for pregnancy complications. High-level PA was associated with decreased risk of gestational diabetes mellitus (GDM) [8] and low-level PA was associated with increased risk of preterm delivery [9]. Maternal exercise intervention also decreased risk of gestational hypertension and macrosomia [10]. These pregnancy complications could increase the risk of $C D$, suggesting that PA was likely to associate with $\mathrm{CD}$. A prospective cohort study found that women with low PA levels had higher rates of elective $C D$ and emergency $C D$ [11]. While two meta-analyses of randomized controlled trials failed to generate consistent findings regarding the effects of PA on $\mathrm{CD}$; one found that planned aerobic exercise resulted in a significantly lower incidence of CD [12] while the other found that prenatal exercise had no effects on $C D$ [13]. The effects of PA on CD remained inconclusive.

For adults aged 18-64 years, it's recommended to have 7 to 9 hours' sleep per night by the American National Sleep Foundation [14]. It's established that short and/or long sleep duration was associated with placental abruption [15], GDM [16], preeclampsia and hypertension [17], and these medical conditions increase CD risk. Additionally, several studies found that less than $6 \mathrm{~h}$ sleep per day increased CD risk $[18,19]$ while a small cohort study with 200 subjects found that 8 and more hours of sleep per day was associated with a higher rate of assisted deliveries ( $C D$ and instrumental delivery) [20]. Indeed, the association between sleep duration and
CD was less consistent and evidence for excessive sleep duration was insufficient. In addition, Sarah-Jane Paine [21] and Run Li [22] separately reported poor sleep quality increased risk of $\mathrm{CD}$, while an observational study of sleep disturbances failed to find that poor sleep quality was associated with increased risk of CD [23]. Therefore, we also aimed to address the association between sleep quality and $\mathrm{CD}$. In a previous analysis, our group reported that longer sleep duration and low PA increased the risk of GDM [24, 25], which was likely to contribute to a high $C D$ risk. To our knowledge, there were no studies to explore the interactive effects of PA and sleep duration on the risk of CD athough PA was associated with sleep duration [26, 27].

Based on a large population-based prospective cohort of pregnant women in Tianjin, China, the current analyses aimed to explore (1) whether PA and sleep status during pregnancy were associated with CD risk; and (2) whether PA and sleep duration had a synergistic effect on the risk of $\mathrm{CD}$ in Chinese pregnant women.

\section{Methods \\ Study population and settings}

Using an established three-tiered screening and management system for GDM in 1999 in six central urban districts of Tianjin, China [28], our group set up a large population-based cohort of pregnant women and their offspring from October 2010 to August 2012 [29]. A total of 22,302 pregnant women made their first antenatal care visit to primary care hospitals close to their residence during the study period. Among them, we sequentially excluded 233 women with multiple pregnancies, 750 women who delivered stillbirth, 294 women with missing pregnancy outcomes, 701 women with outliers on gestational age and weight gain, 7309 women with missing PA ( $n=$ $6914)$ and sleep duration $(n=395)$. Eventually, 13,015 subjects were included in the analyses (Fig. 1).

\section{Clinical measurements and data collection of potential confounders}

Clinical and biochemical data were collected longitudinally from their first antenatal care visit to delivery by a series of questionnaires or retrieved from the database of the Maternal and Child Health Information System [30]. Information on height, weight, body mass index (BMI), gestational age, 


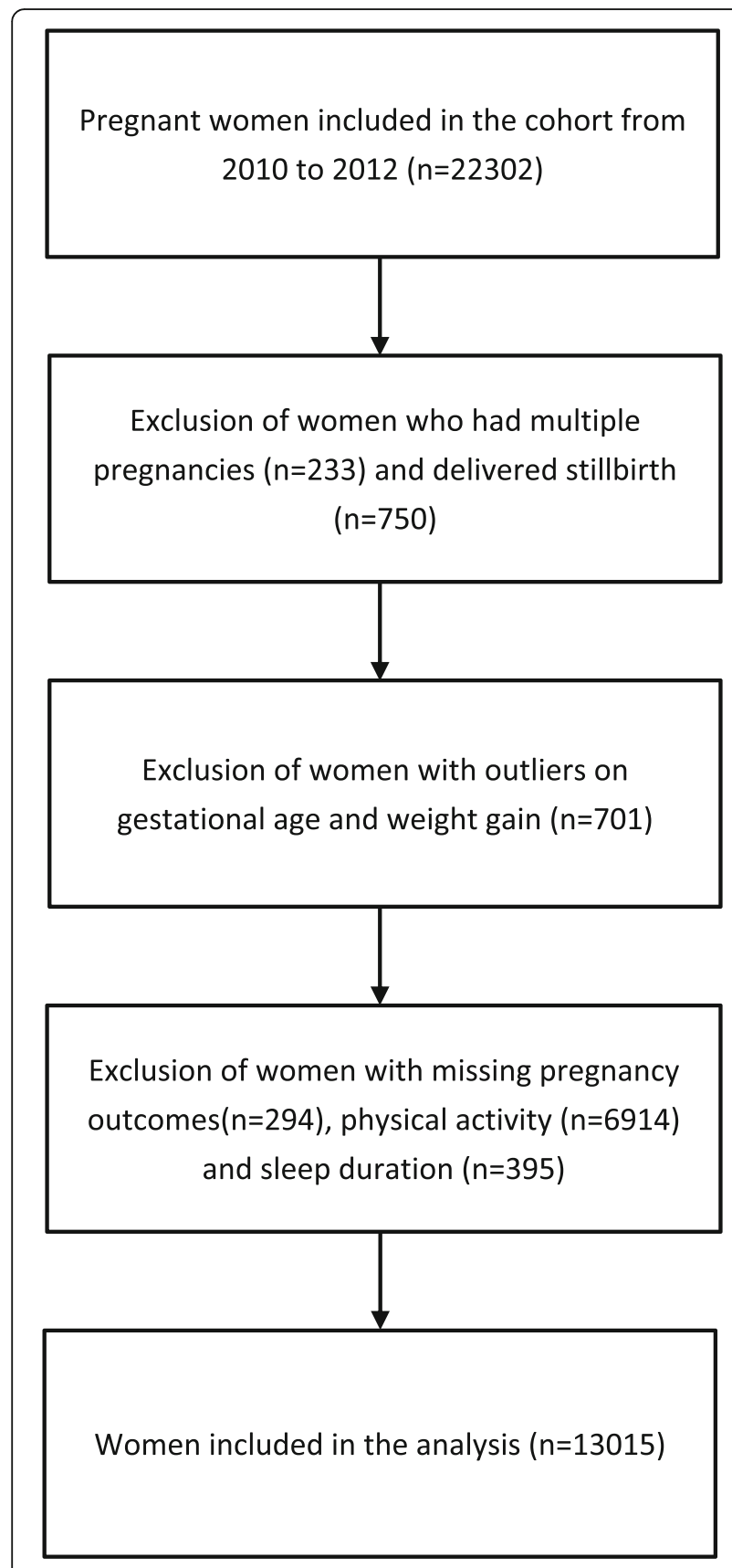

Fig. 1 Study flow diagram of all the exclusions in the cohort

systolic/diastolic blood pressure (SBP/DBP), weight at registration and glucose challenge test (GCT), maternal age, nationality, parity, family history of diabetes in first degree relatives, smoking and drinking habits were measured or collected by care providers. Weight gain was computed as the difference in weight between at the first antenatal care visit and at GCT time. GDM was identified using a twostep procedure: a 50-g 1-h GCT followed by a 75-g 2-h oral glucose tolerance test if the GCT was $7.8 \mathrm{mmol} / \mathrm{L}$ and more [31]. The International Association of Diabetes and
Pregnancy Study Group (IADPSG) criteria were used to diagnose GDM [32].

\section{Assessment of physical activity and sleep status}

PA was collected at the GCT time by a self-reported questionnaire. The questionnaire was used in a study [33] and also used in one of previous analyses of the cohort [25]. The detailed description of the methods and validation information were available elsewhere [34]. To collect data on PA accurately and comprehensively, we further collected information about housework PA. Briefly, occupational, commuting, leisure-time and housework physical activities were documented. Occupational PA was divided into three categories: low (unemployment or work always sitting indoor, e.g. desk work of a secretary), moderate (work with standing, walking or lifting, e.g. waiter), and high (work with heavy manual labor, e.g. industrial workers or athletes). Commuting PA was classified into two categories: low (barely outgoing, using motorized transportation or $<30$ $\mathrm{min} /$ day walking or cycling) and moderate-to-high $(\geq 30$ min/day walking or cycling). Leisure-time PA was divided into two categories: no leisure-time PA or exercise less than $150 \mathrm{~min}$ per week ( $<150 \mathrm{~min} /$ week) and exercise more than $150 \mathrm{~min}$ per week ( $\geq 150 \mathrm{~min} /$ week). Housework PA was divided into $\leq 1 \mathrm{~h} /$ day and $>1 \mathrm{~h} /$ day. To gain a representative indicator of PA, we regrouped PA into two categories based on the four types of activities above: low (low occupational and commuting PA, leisure-time PA $<150 \mathrm{~min} /$ week and housework PA $\leq 1 \mathrm{~h} /$ day), and moderate-to-high (any of the four categories: moderate and high levels of occupational PA, moderate-to-high commuting PA, leisure-time PA $\geq 150 \mathrm{~min} /$ week and housework PA $>1 \mathrm{~h} /$ day).

Sleep items were collected in the same questionnaire at the GCT time. For use in busy clinical settings in this study, we adapted and further modified two questions from a well-validated scale (The Pittsburg Sleep Quality Index, PSQI) for measurement of self-reported sleep duration and quality of sleep [35]. The questions to collect sleep status were 'How many hours did you sleep every day during pregnancy including both day and night time?' and 'How did you feel about your sleep quality during pregnancy: good, moderate or poor?'. To be consistent with the classification of sleep duration in our previous investigation [24], we defined sleep duration into three categories: $<7 \mathrm{~h} /$ day, $\geq 7-<9 \mathrm{~h} /$ day and $\geq 9 \mathrm{~h} /$ day. Sleep quality was classified into three categories: good, moderate and poor.

\section{Definition of caesarean delivery}

$\mathrm{CD}$ status and related information were retrieved from the electronic database of the Maternal and Children's Health Information System. CD was divided into two types, $\mathrm{CD}$ for medical reasons and $\mathrm{CD}$ for non-medical reasons. Medical indications of $\mathrm{CD}$ included fetal distress, cephalopelvic disproportion, scar uterus, abnormal 
fetal position (breech, transverse, etc.), placenta previa, umbilical cord prolapse, placental abruption, gestational severe complications (GDM, gestational hypertensive or other internal diseases), macrosomia, uterine malformation, uterine inertia, hysteromyoma, pathological pelvis, prolonged labor and cervical lesions. Non-medical indications included social factors, family factors and personal factors. $\mathrm{CD}$ without any reasons provided was also classified as the $\mathrm{CD}$ for non-medical reasons.

\section{Statistical analyses}

$\mathrm{R}$ software ( $\mathrm{R}$ version 4.0.0) was used to perform statistical analyses unless specified. A $P$-value of less than 0.05 for the two-tailed test was considered to be statistically significant. Normal distribution of continuous variables was test with Q-Q plots. Continusous variables were presented as mean \pm SD or median (25th percentile, 75th percentile). Analysis of variance (ANOVA) (if the normal distribution and Levene test were not rejected) or the Kruskal-Wallis test where appropriate was used for comparisons of continuous variables among vaginal delivery, $\mathrm{CD}$ for medical reasons and $\mathrm{CD}$ for non-medical reasons. Bonferroni test or Kruskal-Wallis $\mathrm{H}$ test where appropriate was used to perform multiple comparisons. Categorical variables were presented as number (percentages). Chi-squared test or Fisher's exact test where appropriate was used to compare categorical variables among the three groups.

Binary logistic regression was used to obtain the odds ratio (OR) and 95\% confidence interval (CI). At first, we obtained ORs and 95\% CIs of PA and sleep status for CD in univariable analyses (model 1). Then, we adjusted for potential confounding factors (model 2), including maternal age (continuous), BMI (continuous), weight gain from registration to GCT (continuous), gestational age at delivery (continuous), habitual smokers before and during pregnancy, alcohol drinkers before and during pregnancy, family history of diabetes, parity, ethnicity, SBP (continuous), birth weight (continuous) and neonatal height (continuous). Those confounding factors were selected for being statistically siginifanct different between the $\mathrm{CD}$ group and the non-CD group or considering having clinical significance for $\mathrm{CD}$ by researchers. Because PA and sleep status were risk factors of GDM, we further adjusted for GDM status to check whether GDM played an intermediate role in the associations of PA and sleep status with CD (model 3).

Subgroup analyses were carried out to examine the consistency in the effects of low PA on CD among different sleep duration groups, and the effects of excessive sleep duration on CD among different PA groups. Short sleep duration was not further analyzed because it was not significant in univariate and multivariate analyses. Synergistic effects between PA and sleep duration on CD risk were checked using additive interaction. Three indicators were used to evaluate additive interaction: relative excess risk due to interaction (RERI), attributable proportion due to interaction (AP) or synergy index (S). Relative excess risk due to interaction $>0$, attributable proportion due to interaction $>0$ or synergy index $>1$ was regarded as significant additive interaction [36].

To further check different effects of PA, sleep status and their interactive effects on $\mathrm{CD}$ for medical reasons and non-medical reasons, we further performed multinomial logistic regression with two response levels, $C D$ for medical reasons and $\mathrm{CD}$ for non-medical reasons using the Statistical Analysis System (SAS) release 9.3 (SAS Institute Inc., Cary, NC, USA).

Additional analyses were perfomed to check potential bias in the main analyses. First, we compared the clinical and biochemical characteristics of women excluded and those included in the analyses. Second, we re-included 979 women who had multiple pregnancies or delivered stillbirth to check the impacts of exclusion of those women on the main findings. Third, we analyzed the effect of PA classes, i.e., occupational, commuting, leisuretime and housework physical activities, on the risk of $\mathrm{CD}$ for medical reasons and $\mathrm{CD}$ for non-medical reasons to further explore the specific effect of PA classes.

\section{Results}

\section{Characteristics of the study population}

The mean age of 13,015 pregnant women was 28.5 (standard deviation, SD: 2.9 ) years, with $96.3 \%$ of them being primipara. The mean gestation age at registration was 10 (SD: 2.3) weeks. The mean pre-pregnancy BMI was 22.3 (SD: 3.4$) \mathrm{kg} / \mathrm{m}^{2}$ and they delivered an infant at a means of 39.1 (SD: 1.5) weeks of gestation. A total of 8333 women (64.0\%) had CD. The CD rates for medical reasons and non-medical reasons were 43.7 and $20.3 \%$, respectively. The main medical indications of $\mathrm{CD}$ were cephalopelvic disproportion (32.8\%), fetal distress (18.7\%), others (18.0\%), social factors (5.8\%), and breech presentation (5.0\%). Women with CD for medical reasons or nonmedical reasons were older, had higher pre-pregnancy BMI, SBP and DBP, and more likely to smoke and have a family history of diabetes than women without CD. Infants born by $\mathrm{CD}$ had higher weight and height. Women with $\mathrm{CD}$ were more likely to have low PA and excessive sleep duration. Individually, women with $\mathrm{CD}$ for medical reasons or non-medical reasons had lower levels of occupational PA, commuting PA, leisure-time PA, housework $\mathrm{PA}$, and longer sleep duration, while sleep quality were similar among the three groups (Table 1).

\section{Physical activity and sleep status for caesarean delivery risk}

Using moderate-to-high PA as the reference, the unadjusted OR and adjusted OR of low PA for CD were 1.10 (95\%CI: $1.03-1.19$ ) and 1.12 (95\%CI: $1.03-1.21$ ), 
Table 1 Clinical and biochemical characteristics of subjects by three different delivery types

\begin{tabular}{|c|c|c|c|c|}
\hline Variables & Vaginal delivery & CD for medical reasons & CD for non-medical reasons & $P$-value \\
\hline$n$ & 4682 & 5692 & 2641 & \\
\hline \multicolumn{5}{|l|}{ Variables at registration for pregnancy } \\
\hline Age, year & $28.07 \pm 2.60^{\dagger, \neq}$ & $28.72 \pm 3.04^{\dagger}$ & $28.66 \pm 3.11^{\ddagger}$ & $<0.001^{*}$ \\
\hline Pre-pregnancy BMl, kg/m² & $21.56 \pm 2.97^{\dagger, \neq}$ & $22.81 \pm 3.54^{\dagger}$ & $22.62 \pm 3.48^{\ddagger}$ & $<0.001^{*}$ \\
\hline Han-nationality & 4481 (95.7\%) & $5404(94.9 \%)$ & $2516(95.3 \%)$ & $0.186^{* *}$ \\
\hline Weight, kg & $57.82 \pm 8.68^{\dagger, \neq}$ & $60.67 \pm 10.20^{t, \S}$ & $60.09 \pm 10.04^{\ddagger, \S}$ & $<0.001^{*}$ \\
\hline Height, cm & $163.68 \pm 4.55^{\dagger, \neq}$ & $162.99 \pm 4.82^{\dagger}$ & $162.88 \pm 4.74^{\ddagger}$ & $<0.001^{*}$ \\
\hline Systolic blood pressure, $\mathrm{mmHg}$ & $104.80 \pm 10.38^{\dagger, \neq}$ & $106.24 \pm 10.82^{\dagger}$ & $106.22 \pm 11.10^{\ddagger}$ & $<0.001^{*}$ \\
\hline Diastolic blood pressure, $\mathrm{mmHg}$ & $67.73 \pm 7.50^{\dagger, \neq}$ & $68.95 \pm 7.83^{\dagger}$ & $69.00 \pm 8.05^{\ddagger}$ & $<0.001^{*}$ \\
\hline Parity $\geq 1$ & $138(2.9 \%)$ & $249(4.4 \%)$ & 97 (3.7\%) & $0.001^{* *}$ \\
\hline Family history of diabetes in first degree relatives & $364(8.3 \%)$ & $538(10.0 \%)$ & $223(9.1 \%)$ & $0.014^{* *}$ \\
\hline Gestational age at registration, weeks & $10.45 \pm 2.40^{\dagger}$ & $10.32 \pm 2.31^{\dagger}$ & $10.39 \pm 2.27$ & $0.008^{*}$ \\
\hline History of caesarean delivery $\geq 1$ & $5(0.1 \%)$ & $193(3.4 \%)$ & $64(2.4 \%)$ & $<0.001^{* *}$ \\
\hline \multicolumn{5}{|l|}{ Variables at Glucose challenge test } \\
\hline Smoke before or during pregnancy & $119(2.5 \%)$ & $326(5.7 \%)$ & $162(6.1 \%)$ & $<0.001^{* *}$ \\
\hline Drink before or during pregnancy & $1462(31.2 \%)$ & $1818(31.9 \%)$ & $846(32.0 \%)$ & $0.680^{* *}$ \\
\hline Gestational diabetes mellitus & $261(5.9 \%)$ & $453(8.4 \%)$ & $183(7.4 \%)$ & $<0.001^{* *}$ \\
\hline Glucose challenge test, $\mathrm{mmol} / \mathrm{L}$ & $6.49 \pm 1.50^{\dagger, \neq}$ & $6.72 \pm 1.60^{+}$ & $6.71 \pm 1.56^{\ddagger}$ & $<0.001^{*}$ \\
\hline Weight gain from registration to $\mathrm{GCT}, \mathrm{kg}$ & $7.41 \pm 3.02^{\dagger, \neq}$ & $7.81 \pm 3.58^{\dagger}$ & $7.72 \pm 3.18^{\ddagger}$ & $<0.001^{*}$ \\
\hline Occupational physical activity & & & & $0.347^{* *}$ \\
\hline Low & $4022(86.0 \%)$ & $4946(86.9 \%)$ & $2289(86.7 \%)$ & \\
\hline Moderate-to-high & $656(14.0 \%)$ & $743(13.1 \%)$ & $351(13.3 \%)$ & \\
\hline Commuting physical activity(min/day) ${ }^{a}$ & & & & $0.003^{* *}$ \\
\hline low & $4374(93.6 \%)$ & $5386(94.7 \%)$ & $2513(95.4 \%)$ & \\
\hline Moderate-to-high & $301(6.4 \%)$ & $302(5.3 \%)$ & $122(4.6 \%)$ & \\
\hline Leisure-time physical activity(min/week) & & & & $0.123^{* *}$ \\
\hline 0 & $2477(53.1 \%)$ & $3074(54.3 \%)$ & $1474(56.0 \%)$ & \\
\hline $0-150$ & $1391(29.8 \%)$ & $1657(29.2 \%)$ & $716(27.2 \%)$ & \\
\hline$\geq 150$ & $797(17.1 \%)$ & $935(16.5 \%)$ & $441(16.8 \%)$ & \\
\hline Housework physical activity(h/day) & & & & $0.007^{* *}$ \\
\hline$\leq 1$ & $3544(77.6 \%)$ & $4432(79.9 \%)$ & $2008(77.6 \%)$ & \\
\hline$>1$ & $1022(22.4 \%)$ & $1114(20.1 \%)$ & $579(22.4 \%)$ & \\
\hline \multicolumn{5}{|l|}{ Physical activity during pregnancy ${ }^{b}$} \\
\hline Low & $2454(52.4 \%)$ & $3147(55.3 \%)$ & $1427(54.0 \%)$ & $0.014^{* *}$ \\
\hline Moderate-to-high & $2228(47.6 \%)$ & $2545(44.7 \%)$ & $1214(46.0 \%)$ & \\
\hline Sleep duration during pregnancy(h/day) & & & & $0.025^{* *}$ \\
\hline$<7$ & $88(1.9 \%)$ & $98(1.7 \%)$ & $65(2.5 \%)$ & \\
\hline$\geq 7$ to $<9$ & $2067(44.1 \%)$ & $2410(42.3 \%)$ & $1091(41.3 \%)$ & \\
\hline$\geq 9$ & $2527(54.0 \%)$ & $3184(55.9 \%)$ & $1485(56.2 \%)$ & \\
\hline Sleep quality during pregnancy & & & & $0.872^{* *}$ \\
\hline Good & $1762(37.7 \%)$ & $2161(38.1 \%)$ & $990(37.6 \%)$ & \\
\hline Moderate & $2792(59.8 \%)$ & $3390(59.8 \%)$ & $1583(60.1 \%)$ & \\
\hline Poor & $114(2.4 \%)$ & $122(2.2 \%)$ & $63(2.4 \%)$ & \\
\hline
\end{tabular}


Table 1 Clinical and biochemical characteristics of subjects by three different delivery types (Continued)

\begin{tabular}{lllll}
\hline Variables & Vaginal delivery & CD for medical reasons & CD for non-medical reasons & $P$-value \\
\hline Variables at delivery & & & & \\
Gestational age at delivery, weeks & $39.09 \pm 1.60^{\dagger}$ & $39.06 \pm 1.40^{\dagger, \S}$ & $39.13 \pm 1.52^{\S}$ & $<0.001^{*}$ \\
Birth weight, kg & $3.28 \pm 0.42^{\dagger, \ddagger}$ & $3.46 \pm 0.49^{\dagger, \S}$ & $3.40 \pm 0.45^{\ddagger, \S}$ & $<0.001^{*}$ \\
Neonatal height, cm & $50.03 \pm 1.67^{\dagger, \ddagger}$ & $50.21 \pm 1.63^{\dagger}$ & $50.22 \pm 1.60^{\ddagger}$ & $<0.001^{*}$ \\
\hline
\end{tabular}

Abbreviations: BMI body mass index; GCT glucose challenge test; $C D$ caesarean delivery

*Derived from analyses of variance (ANOVA) or the Kruskal-Wallis test;

**Derived from Chi-square Test or Fisher's exact test

For analyses of continuous variables, Bonferroni test or Kruskal-Wallis $\mathrm{H}$ test was used to perform multiple comparisons with identical $\dagger$, $\ddagger$, or $\S$ indicating

statistically significant differences between two means

${ }^{a}$ Low was defined was defined barely outgoing, using motorized transportation or $<30 \mathrm{~min} /$ day walking or cycling to and from work

${ }^{b}$ Low was defined when subjects simultaneously reported the light level of occupational physical activity, low commuting physical activity, < 150 min/week of

leisure-time physical activity, and $\leq 1 \mathrm{~h} /$ day housework physical activity; and others were defined as 'moderate-to-high'

respectively. Compared to sleep duration from $\geq 7$ to $<9 \mathrm{~h} /$ day, sleep duration $<7 \mathrm{~h}$ /day was not associated with CD risk while sleep duration $\geq 9 \mathrm{~h}$ /day was significantly associated with increased risks of CD (unadjusted OR: 1.09, 95\% CI: 1.01-1.17 \& adjusted OR: 1.13, 95\%CI: 1.04-1.22). Using good sleep quality as the reference, moderate and poor sleep quality were not associated with $C D$ risk. Further adjustment for GDM status did not significantly attenuate the effect size of PA and sleep duration for CD (Table 2).

\section{Additive interaction between physical activity and sleep duration for caesarean delivery}

Compared to moderate-to-high PA, low PA was not associated with $\mathrm{CD}$ risk among women with sleep duration $<9$ h/day. However, the unadjusted and adjusted ORs of low PA were significant among women with sleep duration $\geq 9 \mathrm{~h} /$ day (unadjusted OR:
1.16, 95\%CI: $1.06-1.28$ \& adjusted OR: $1.20,95 \% \mathrm{CI}$ : 1.08-1.34).

Among women with low PA, the unadjusted and adjusted ORs of sleep duration $\geq 9 \mathrm{~h}$ /day for $\mathrm{CD}$ were 1.15 (95\%CI:1.04-1.27) and 1.21 (95\%CI:1.09-1.35), respectively. Among women with moderate-to-high PA, sleep duration $\geq 9 \mathrm{~h} /$ day was not associated with the risk of CD.

Using the moderate-to-high PA and sleep duration $<9$ $\mathrm{h}$ /day as the reference, presence of low PA alone and sleep time $\geq 9 \mathrm{~h} /$ day alone were not associated with increased risk of CD. However, co-presence of low PA and sleep duration $\geq 9 \mathrm{~h} /$ day significantly increased the risk of CD (adjusted OR: 1.25, 95\%CI: 1.12-1.41) with significant additive interaction (Relative excess risk due to interaction: 0.17, 95\%CI: 0.01-0.34; Attributable proportion due to interaction: 0.14, 95\%CI: 0.01-0.27). The additive interaction between low PA and sleep duration

Table 2 ORs of physical activity and sleep status during pregnancy for caesarean delivery

\begin{tabular}{|c|c|c|c|c|}
\hline \multirow[t]{2}{*}{ Variables } & \multirow[t]{2}{*}{ n (\%) } & \multicolumn{3}{|l|}{ OR $(95 \% \mathrm{Cl})$} \\
\hline & & Model 1 & Model 2 & Model 3 \\
\hline \multicolumn{5}{|l|}{ Physical activity } \\
\hline Low & $4574(35.1 \%)$ & $1.10(1.03-1.19)$ & $1.12(1.03-1.21)$ & $1.12(1.04-1.22)$ \\
\hline Moderate-to-high & 3759 (28.9\%) & 1.00 (Reference) & 1.00 (Reference) & 1.00 (Reference) \\
\hline \multicolumn{5}{|l|}{ Sleep duration (h/day) } \\
\hline$<7$ & $163(1.3 \%)$ & $1.09(0.84-1.43)$ & $1.05(0.79-1.41)$ & $1.04(0.78-1.39)$ \\
\hline$\geq 7$ to $<9$ & 3501 (26.9\%) & 1.00 (Reference) & 1.00 (Reference) & 1.00 (Reference) \\
\hline$\geq 9$ & 4669 (35.9\%) & $1.09(1.01-1.17)$ & $1.13(1.04-1.22)$ & $1.13(1.04-1.22)$ \\
\hline \multicolumn{5}{|l|}{ Sleep quality } \\
\hline Good & 3151 (24.2\%) & 1.00 (Reference) & 1.00 (Reference) & 1.00 (Reference) \\
\hline Moderate & 4973 (38.2\%) & $1.00(0.92-1.07)$ & $0.99(0.91-1.07)$ & $1.00(0.92-1.09)$ \\
\hline Poor & 185 (1.4\%) & $0.91(0.71-1.16)$ & $0.88(0.68-1.14)$ & $0.91(0.70-1.19)$ \\
\hline
\end{tabular}

Abbreviations: $n \%$ number of cases (\% of number at risk); OR odds ratio; $\mathrm{Cl}$ confidence interval

Model 1: Univariable analyses

Model 2: Multivariable analyses, adjusted for age, body mass index, weight gain from registration to glucose challenge test, gestational age at delivery, habitual smokers before and during pregnancy, alcohol drinkers before and during pregnancy, family history of diabetes in first-degree relatives, parity $\geq 1$, Han nationality, systolic blood pressure at registration for pregnancy, birth weight, neonatal height

Model 3: Further adjusted for gestational diabetes, in addition to the variables listed in model 2 
$\geq 9 \mathrm{~h} /$ day for CD persisted after adjustment for GDM (Table 3).

\section{Physical activity and sleep status for risk of caesarean delivery for medical reasons and non-medical reasons} Low PA was associated with increased risk of CD for medical reasons (adjusted OR:1.13, 95\%CI: 1.04-1.23) but not associated with $\mathrm{CD}$ for non-medical reasons. Sleep duration $\geq 9 \mathrm{~h}$ /day was associated with increased risk of both $\mathrm{CD}$ for medical reasons (adjusted OR: 1.12, 95\%CI: $1.02-1.22$ ) and CD for non-medical reasons (adjusted OR:1.16, 95\%CI: 1.05-1.29). However, sleep duration $<7 \mathrm{~h} /$ day and sleep quality were not associated with increased risk of either $\mathrm{CD}$ for medical reasons or CD for non-medical reasons (Table 4).

Additive interaction between physical activity and sleep duration for risk of caesarean delivery for medical reasons and non-medical reasons

Co-presence of low PA and sleep duration $\geq 9$ h/day was associated with elevated risk of $\mathrm{CD}$ for medical reasons (adjusted OR: 1.35, 95\%CI: 1.17-1.55) with significant additive interaction (Relative excess risk due to interaction: 0.26, 95\%CI: 0.06-0.45; Attributable proportion due to interaction: $0.19,95 \% \mathrm{CI}: 0.05-0.33)$. However, their additive interaction for $\mathrm{CD}$ for non-medical reasons was not significant (Table 5).

\section{Sensitivity analyses}

There were statistical differences in some of the variables between the included women and those excluded from the analyses, including age, BMI, weight, SBP, parity, alcohol drinking habit, GDM, weight gain from registration to $\mathrm{GCT}$, sleep duration, gestational age at delivery, birth weight and fetal height (eTable 1). Reinclusion of the 979 women who had multiple pregnancies or delivered stillbirth did not substantially change the effect sizes of $\mathrm{PA}$ and sleep duration for $\mathrm{CD}$ (eTable 2). Using moderate-to-high commuting PA as the reference, low commuting PA was associated with $\mathrm{CD}$ for non-medical reasons but not with $\mathrm{CD}$ for medical reasons. On the contrary, $\leq 1 \mathrm{~h} /$ day housework was associated with increased risk of $\mathrm{CD}$ for medical reasons but not $\mathrm{CD}$ for non-medical reasons. On the other hand, occupational PA and leisure-time PA were not associated with altered risk of $\mathrm{CD}$ for medical reasons and $\mathrm{CD}$

Table 3 Subgroup and additive interaction analyses of physical activity and sleep duration for CD

\begin{tabular}{|c|c|c|c|}
\hline \multirow[t]{2}{*}{ Variables } & \multicolumn{3}{|l|}{ OR $(95 \% \mathrm{Cl})$} \\
\hline & Model 1 & Model 2 & Model 3 \\
\hline \multicolumn{4}{|l|}{ Subgroup analyses } \\
\hline \multicolumn{4}{|l|}{ Among sleep time $<9$ h/day } \\
\hline Low V.S Moderate-to-high PA & $1.04(0.94-1.16)$ & $1.04(0.92-1.17)$ & $1.03(0.91-1.16)$ \\
\hline \multicolumn{4}{|l|}{ Among sleep time $\geq 9 \mathrm{~h} /$ day } \\
\hline Low V.S Moderate-to-high PA & $1.16(1.06-1.28)$ & $1.20(1.08-1.34)$ & $1.22(1.09-1.36)$ \\
\hline \multicolumn{4}{|l|}{ Among low PA } \\
\hline$\geq 9$ h/day V.S $<9$ h/day sleep time & $1.15(1.04-1.27)$ & $1.21(1.09-1.35)$ & $1.22(1.10-1.37)$ \\
\hline \multicolumn{4}{|l|}{ Among moderate-to-high PA } \\
\hline$\geq 9$ h/day V.S $<9$ h/day sleep time & $1.03(0.92-1.14)$ & $1.03(0.92-1.16)$ & $1.02(0.90-1.15)$ \\
\hline \multicolumn{4}{|l|}{ Additive interaction models } \\
\hline Moderate-to-high PA and sleep time $<9 \mathrm{~h} /$ day & 1.00 (Reference) & 1.00 (Reference) & 1.00 (Reference) \\
\hline Low PA and sleep time $<9 \mathrm{~h} /$ day & $1.04(0.94-1.16)$ & $1.04(0.92-1.16)$ & $1.03(0.91-1.16)$ \\
\hline Moderate-to-high PA and sleep time $\geq 9 /$ day & $1.03(0.92-1.14)$ & $1.04(0.93-1.17)$ & $1.03(0.92-1.16)$ \\
\hline Low PA and sleep time $\geq 9 \mathrm{~h} /$ day & $1.20(1.08-1.33)$ & $1.25(1.12-1.41)$ & $1.25(1.12-1.41)$ \\
\hline \multicolumn{4}{|l|}{ Additive interaction indications } \\
\hline RERI & $0.13(-0.02-0.28)$ & $0.17(0.01-0.34)$ & $0.20(0.03-0.36)$ \\
\hline AP & $0.11(-0.02-0.23)$ & $0.14(0.01-0.27)$ & $0.16(0.02-0.29)$ \\
\hline$S$ & $2.85(0.24-33.50)$ & $3.20(0.30-34.42)$ & $4.40(0.15-130.67)$ \\
\hline
\end{tabular}

Abbreviations: $C D$ caesarean delivery; $P A$ physical activity; $R E R E$ relative excess risk due to interaction; $A P$ attributable proportion due to interaction and $S$ synergy index. $\mathrm{RERI}>0, \mathrm{AP}>0$, or $\mathrm{S}>1$ suggest significant additive interaction; $O R$ odds ratio; $C l$ confidence interval

Model 1: Univariable analyses

Model 2: Multivariable analyses, adjusted for age, body mass index, weight gain from registration to glucose challenge test, gestational age at delivery, habitual smokers before and during pregnancy, alcohol drinkers before and during pregnancy, family history of diabetes in first-degree relatives, parity $\geq 1$, Han nationality, systolic blood pressure at registration for pregnancy, birth weight, neonatal height

Model 3: Further adjusted for gestational diabetes, in addition to the variables listed in model 2 
Table 4 ORs of Physical activity and sleep status for CD for medical reasons and non-medical reasons

\begin{tabular}{|c|c|c|c|}
\hline \multirow[t]{2}{*}{ Variables } & & \multicolumn{2}{|c|}{ OR (95\% confidence interval) } \\
\hline & & CD for medical reasons & CD for non-medical ressons rereasons \\
\hline \multirow[t]{10}{*}{ Model 1} & Physical activity & & \\
\hline & Low V.S Moderate-to-high & $1.12(1.04-1.21)$ & $1.07(0.97-1.17)$ \\
\hline & Sleep duration (h/day) & & \\
\hline & $<7$ & $0.96(0.71-1.28)$ & $1.40(1.01-1.95)$ \\
\hline & $\geq 7$ to $<9$ & 1.00 (Reference) & 1.00 (Reference) \\
\hline & $\geq 9$ & $1.08(0.99-1.17)$ & $1.11(1.01-1.23)$ \\
\hline & Sleep quality & & \\
\hline & Good & 1.00 (Reference) & 1.00 (Reference) \\
\hline & Moderate & $0.99(0.91-1.07)$ & $1.01(0.91-1.11)$ \\
\hline & Poor & $0.87(0.67-1.14)$ & $0.98(0.72-1.35)$ \\
\hline \multirow[t]{10}{*}{ Model 2} & Physical activity & & \\
\hline & Low V.S Moderate-to-high & $1.13(1.04-1.23)$ & $1.10(0.99-1.22)$ \\
\hline & Sleep duration (h/day) & & \\
\hline & $<7$ & $0.90(0.65-1.24)$ & $1.37(0.96-1.94)$ \\
\hline & $\geq 7$ to $<9$ & 1.00 (Reference) & 1.00 (Reference) \\
\hline & $\geq 9$ & $1.12(1.02-1.22)$ & $1.16(1.05-1.29)$ \\
\hline & Sleep quality & & \\
\hline & Good & 1.00 (Reference) & 1.00 (Reference) \\
\hline & Moderate & $0.98(0.90-1.07)$ & $0.99(0.89-1.11)$ \\
\hline & Poor & $0.85(0.64-1.13)$ & $0.93(0.66-1.31)$ \\
\hline \multirow[t]{10}{*}{ Model 3} & Physical activity & & \\
\hline & Low V.S Moderate-to-high & $1.13(1.04-1.24)$ & $1.11(0.99-1.23)$ \\
\hline & Sleep duration (h/day) & & \\
\hline & $<7$ & $0.88(0.64-1.22)$ & $1.37(0.96-1.95)$ \\
\hline & $\geq 7$ to $<9$ & 1.00 (Reference) & 1.00 (Reference) \\
\hline & $\geq 9$ & $1.12(1.02-1.22)$ & $1.16(1.04-1.29)$ \\
\hline & Sleep quality & & \\
\hline & Good & 1.00 (Reference) & 1.00 (Reference) \\
\hline & Moderate & $0.99(0.91-1.09)$ & $1.01(0.91-1.13)$ \\
\hline & Poor & $0.88(0.66-1.18)$ & $0.98(0.69-1.38)$ \\
\hline
\end{tabular}

Abbreviations: $C D$ caesarean delivery; $O R$ odds ratio

Model 1: Univariable analyses

Model 2: Multivariable analyses, adjusted for age, body mass index, weight gain from registration to glucose challenge test, gestational age at delivery, habitual smokers before and during pregnancy, alcohol drinkers before and during pregnancy, family history of diabetes in first-degree relatives, parity $\geq 1$, Han nationality, systolic blood pressure at registration for pregnancy, birth weight, neonatal height

Model 3: Further adjusted for gestational diabetes, in addition to the variables listed in model 2

for non-medical reasons (eTable 3). More detailed information is available in these tables (see eTables $1,2,3$ ).

\section{Discussion}

Our study revealed that (1) low PA and excessive sleep duration during pregnancy were two risk factors for $\mathrm{CD}$; (2) there was a significant synergistic effect of low PA and excessive sleep duration on the risk of $\mathrm{CD}$ for medical reasons and overall CD; (3) low PA increased risk of $\mathrm{CD}$ for medical reasons while excessive sleep duration increased the risk of both $\mathrm{CD}$ for medical reasons and non-medical reasons.

\section{Implications}

Some studies investigated the association between PA and $\mathrm{CD}$ but their findings were inconsistent. A prospective longitudinal study with 94 Caucasian pregnant women failed to observe any differences in PA levels during the early second trimester of pregnancy between women with vaginal delivery and those with $\mathrm{CD}$ [37]. A 
Table 5 Additive interaction of physical activity and sleep duration on CD for medical and non-medical reasons

\begin{tabular}{|c|c|c|c|}
\hline \multirow[t]{2}{*}{ Variables } & & \multicolumn{2}{|l|}{ OR $(95 \% \mathrm{Cl})$} \\
\hline & & CD for medical reasons & $C D$ for non-medical reasons \\
\hline \multirow[t]{9}{*}{ Model 1} & Additive interaction & & \\
\hline & Moderate-to-high PA and sleep time $<9$ h/day & 1.00(Reference) & 1.00(Reference) \\
\hline & Low PA and sleep time $<9 \mathrm{~h} /$ day & $1.07(0.96-1.19)$ & $1.07(0.93-1.22)$ \\
\hline & Moderate-to-high PA and sleep time $\geq 9 /$ day & $1.00(0.89-1.12)$ & $1.08(0.94-1.25)$ \\
\hline & Low PA and sleep time $\geq 9 \mathrm{~h} /$ day & $1.27(1.12-1.44)$ & $1.24(1.05-1.45)$ \\
\hline & Additive interaction indications & & \\
\hline & RERI & $0.20(0.03-0.37)$ & $0.09(-0.13-0.31)$ \\
\hline & AP & $0.16(0.03-0.29)$ & $0.07(-0.10-0.25)$ \\
\hline & S & $3.98(0.26-61.04)$ & $1.60(0.37-6.99)$ \\
\hline \multirow[t]{9}{*}{ Model 2} & Additive interaction & & \\
\hline & Moderate-to-high PA and sleep time $<9 \mathrm{~h} /$ day & 1.00(Reference) & 1.00(Reference) \\
\hline & Low PA and sleep time $<9$ h/day & $1.06(0.95-1.20)$ & $1.09(0.95-1.26)$ \\
\hline & Moderate-to-high PA and sleep time $\geq 9 /$ day & $1.02(0.90-1.15)$ & $1.11(0.95-1.29)$ \\
\hline & Low PA and sleep time $\geq 9 \mathrm{~h} /$ day & $1.34(1.16-1.54)$ & $1.36(1.14-1.61)$ \\
\hline & Additive interaction indications & & \\
\hline & RERI & $0.26(0.06-0.45)$ & $0.15(-0.09-0.40)$ \\
\hline & AP & $0.19(0.05-0.33)$ & $0.11(-0.06-0.29)$ \\
\hline & S & $4.13(0.35-48.48)$ & $1.75(0.54-5.67)$ \\
\hline \multirow[t]{9}{*}{ Model 3} & Additive interaction & & \\
\hline & Moderate-to-high PA and sleep time $<9 \mathrm{~h} /$ day & 1.00(Reference) & 1.00(Reference) \\
\hline & Low PA and sleep time $<9 \mathrm{~h} /$ day & $1.07(0.95-1.20)$ & $1.07(0.93-1.24)$ \\
\hline & Moderate-to-high PA and sleep time $\geq 9 /$ day & $1.01(0.89-1.15)$ & $1.08(0.92-1.26)$ \\
\hline & Low PA and sleep time $\geq 9 \mathrm{~h} /$ day & $1.34(1.16-1.54)$ & $1.36(1.14-1.62)$ \\
\hline & Additive interaction indications & & \\
\hline & RERI & $0.26(0.06-0.45)$ & $0.21(-0.04-0.45)$ \\
\hline & AP & $0.19(0.05-0.33)$ & $0.15(-0.02-0.33)$ \\
\hline & S & $4.21(0.32-56.28)$ & 2.36(0.47-11.79) \\
\hline
\end{tabular}

Abbreviations: $C D$ caesarean delivery; RERE relative excess risk due to interaction; $A P$ attributable proportion due to interaction and $\mathrm{S}$, synergy index. RERI $>0, \mathrm{AP}>$ 0 , or $\mathrm{S}>1$ suggest significant additive interaction; $O R$ odds ratio; $\mathrm{Cl}$ confidence interval Model 1: Univariable analyses

Model 2: Multivariable analyses, adjusted for age, body mass index, weight gain from registration to glucose challenge test, gestational age at delivery, habitual smokers before and during pregnancy, alcohol drinkers before and during pregnancy, family history of diabetes in first-degree relatives, parity $\geq 1$, Han nationality, systolic blood pressure at registration for pregnancy, birth weight, neonatal height

Model 3: Further adjusted for gestational diabetes, in addition to the variables listed in model 2

secondary analysis of a cluster-randomized trial in Germany $(n=1994)$ showed that lack of PA before or during 12th week of gestation increased risk of CD [38]. A large population-based cohort study with 39,187 Norway nulliparous singleton women found that exercise during pregnancy was associated with a reduced risk of acute $C D$ and high exercise frequency in the 30th week of pregnancy was associated with the greatest risk reduction for elective $\mathrm{CD}$ [39]. The differences in period, intensity and types of PA in these studies might be the main reason for these inconsistent findings. In this regard, our study found that low PA increased the risk of
CD for medical reasons and overall $C D$ but not $C D$ for non-medical reasons in Chinese pregnant women.

Previous studies also reported inconsistent findings regarding the association of sleep quality and sleep duration with $C D$. A prospective observational study ( $n=131)$ found that poor sleep quality and $<6 \mathrm{~h}$ of sleep per day were significantly associated with risk of CD [40]. A meta-analysis of sleep disturbances during pregnancy reported that poor sleep quality and long sleep duration significantly increased risk of $C D$, while short sleep duration was not associated with CD [41]. A cohort study $(n=200)$ revealed that 
assisted deliveries, defined as a composite endpoint of $\mathrm{CD}$ and instrumental delivery, were more frequent among women with $>8 \mathrm{~h} /$ night sleep while $\mathrm{CD}$ alone was more frequent among women with $<6.5 \mathrm{~h} /$ night sleep [20]. In our study, poor sleep quality and short sleep duration were not significant for $C D$, possibly due to their low prevalence in our cohort (i.e., 2.3 and $1.9 \%$, respectively). However, our study did find that sleep duration $\geq 9 \mathrm{~h}$ /day increased risk of $C D$ for medical reasons and non-medical reasons. In addition, given to inconsistency in the definition of long sleep duration in previous studies [42], we also performed the same analyses using $\geq 10 \mathrm{~h}$ of sleep per day as excessive sleep duration and found that sleep duration $\geq 10 \mathrm{~h} /$ day had similar effects on $C D$ after adjusting for confounding factors (OR:1.18, 95\%CI:1.08-1.29). Excessive sleep duration increased risk of a number of pregnancy complications such as GDM [34], preeclampsia and hypertension [17], late stillbirth [43], and preterm birth [44]. Therefore, avoiding excessive sleep duration might be an important antenatal practice not only to lower the risk of $\mathrm{CD}$ but also to reduce other pregnancy complications such as GDM [23].

To our knowledge, there were no studies, to date, reporting interactive effects of $\mathrm{PA}$ and sleep duration during pregnancy on the risk of $\mathrm{CD}$. Our study revealed a significant additive interactive effect of low PA and sleep duration $\geq 9 \mathrm{~h} /$ day towards increasing the risk of $\mathrm{CD}$. The additive interaction effect was only significant for $\mathrm{CD}$ for medical reasons but not $\mathrm{CD}$ for non-medical reasons. Although PA and sleep duration might affect maternal blood glucose metabolism during pregnancy, we did not observe that PA, sleep duration and their interactive effects were mediated via their impacts on GDM. Produced in adipose tissue and placental trophoblasts [45], leptin might be a signaling molecule for placental development and embryonal growth during pregnancy [46]. In early pregnancy, women with physical inactivity or excessive sleep duration were found to have elevated plasma leptin $[47,48]$. A prospective longitudinal study found that pregnancies with adverse outcomes had higher a leptin concentration than uncomplicated pregnancies in the first trimester [49]. Therefore, it remained to be tested whether copresence of physical inactivity and excessive sleep duration during pregnancy was related to aberrant placental development, which leaded to high $\mathrm{CD}$ risk.

China had the highest CD rate in the world, reaching an overall hospital-based rate of $41.1 \%$ in 2016 , and the high $C D$ rate was deemed associated with a high medical expense and overuse of medical recourses in China [5]. The CD rate in our cohort was as high as $64 \%$. In this connection, a study in Guangzhou, China, showed that a two-stage intervention program with population health education, skills training for healthcare professionals, equipment and technical support for local healthcare facilities was able to substantially reduce the $\mathrm{CD}$ rate, i.e., from $42.4 \%$ in 2008 to $35.0 \%$ in 2016 [50]. Our study suggested that either to increase PA or/and to maintain recommended sleep duration may reduce about 19\% risk of $\mathrm{CD}$ for medical reasons due to co-exposure to lack of PA and excessive sleep duration. Such intervention might also have other health benefits such as reduced risk of GDM in the mother and decreased risk of childhood obesity and asthma in the offspring [6]. Indeed, integrated organizational and clinical interventions including health education to pregnant women and professionals are needed to reduce the high $C D$ rate in China, especially in the large cities. PA and sleep should be considered to be included in the intervention package in future intervention studies.

\section{Strenth and limitations}

The major strength of the prospective population-based cohort study was the large sample size, which provided sufficient statistical power to estimate PA, sleep duration and especially for their interactive effect on the risk of $\mathrm{CD}$. Furthermore, our study retrieved the details of the pregnancy outcomes including the indications of $\mathrm{CD}$ from the electronic health system, which provided the possibility to explore the specific effect of PA and sleep status on different types of $\mathrm{CD}$. Additionally, many clinical and biochemical risk factors were available to the analyses so that we could adjust for their potential confounding effects.

Our study had several limitations. First, a high proportion of women (34.1\%) were not included in the analyses due to missing of key variables such as PA and sleep duration, so the selection bias was not avoidable. However, we had carefully adjusted for potential confounders including but not limited to those who were different between women used in the analyses and those women excluded from the analyses, which may have partially removed their confounding effects if any. Second, body weight at delivery was not systematically documented and not available to the analyses and we could only adjust for weight gain from first care visit to GCT time for the confounding effect of weight gain. The confounding effect of weight gain was only partial removed and the residual confounding could not be completely removed. Also, we cannot exclude the possibility that there were other unmeasured factors that had introduced bias. Third, PA and sleep duration were self-reported and the potential self-reporting bias could not be excluded. Fourth, the majority of the women in the analyses were primipara and had singleton live birth and therefore, our findings could not be extrapolated to multiparous and 
multiple pregnancy population of women. Fifth, the CD rate of $64 \%$ in the central urban areas of Tianjin reported in this study was consistent with the $C D$ rate in the population in 2000 [51] but higher than the overall rate in Chinese supercities, i.e., around $50 \%$ and much higher than that in the rural areas [52]. Further validation studies are warranted in other populations, especially in the rural populations.

\section{Conclusions}

The study revealed that low PA and excessive sleep duration during pregnancy increased risk of $\mathrm{CD}$ in a synergistic manner, and the significant additive interaction was due to their interactive effect on the risk of $C D$ for medical reasons. Our results highlighted the significance of increasing PA and maintaining recommended sleep duration during pregnancy for perinatal health. Randomized controlled trials were warranted to confirm the effects of promoting PA and maintaining recommended duration of sleep during pregnancy on the rate of $\mathrm{CD}$ in Chinese population of pregnant women.

\section{Abbreviations}

CD: Caesarean delivery; PA: Physical activity; BMI: Body mass index; SBP: Systolic blood pressure; DBP: Diastolic blood pressure; GDM: Gestational diabetes mellitus; GCT: Glucose challenge test; SD: Standard deviation; OR: Odds ratio; Cl: Confidence interval

\section{Supplementary Information}

The online version contains supplementary material available at https://doi. org/10.1186/s12884-021-03788-4.

Additional file 1 Supplemental tables of sensitivity analyses. Illustrates the details of sensitivity analyses, including eTable S1, eTable S2 and eTable S3.

\section{Acknowledgements}

The authors would like to express our special thanks to obstetricians and other health professionals in the 64 primary care hospitals and 6 district women and children's health care institutes who were involved in the setting up of the cohort. All the authors did not have conflict of interest.

\section{Authors' contributions}

$X . Y$. conceived and designed the study. Y.Y. analyzed the data and wrote the first draft. WQ.L., L.W., J.L., W.L. and S.W provided the study material and patients, collected and assembly the data; All other authors gave critical comments on the manuscript; X.Y. (the corresponding authors) and Y.Y. (the first author) take full responsibility for the work as a whole, including the study design, access to data, and the decision to submit and publish the manuscript. All authors have read and approved the submission of the manuscript; the manuscript has not been published and is not being considered for publication elsewhere, in whole or in part, in any language.

\section{Funding}

This work was supported by the National Key Research and Development Program of China [Grant number: 2018YFC1313900, 2018YFC1313903] and Nature Science Foundation of China [Grant number: 81870549].

\section{Availability of data and materials}

The datasets used and analysed during the current study are available from the corresponding author on reasonable request.

\section{Declarations}

\section{Ethics approval and consent to participate}

This study was approved by the Ethics Committee for Clinical Research of Tianjin Women and Children's Health Centre (TWCHC) on 1 December 2009 (Approval number: 2009-02) and conducted in accordance with Helsiki Declaration. Written informed consent was obtained from all the subjects before data collection and the private information in the study was well protected.

Consent for publication

All the authors agreed to publish the current article.

\section{Competing interests}

All the authors did not have conflict of interest.

\section{Author details}

${ }^{1}$ Department of Epidemiology and Biostatistics, School of Public Health, Tianjin Medical University, P.O. Box 154, 22 Qixiangtai Road, Heping District, Tianjin 300070, China. ${ }^{2}$ Project Office, Tianjin Women and Children's Health Center, Tianjin, China. ${ }^{3}$ Department of Child Health, Tianjin Women and Children's Health Center, Tianjin, China. ${ }^{4}$ Chronic Disease Epidemiology Laboratory, Pennington Biomedical Research Center, Baton Rouge, Louisiana, USA. ${ }^{5}$ Population Cancer Research Program and Department of Pediatrics, Dalhousie University, Halifax, Canada. ${ }^{6}$ Tianjin Key Laboratory of Environment, Nutrition and Public Health, Tianjin, China. ${ }^{7}$ Tianjin Center for International Collaborative Research on Environment, Nutrition and Public Health, Tianjin, China.

Received: 2 December 2020 Accepted: 8 April 2021

Published online: 28 May 2021

\section{References}

1. Stemming the global caesarean section epidemic. Lancet. 2018;392(10155): 1279

2. Boerma T, Ronsmans C, Melesse DY, Barros AJD, Barros FC, Juan L, et al. Global epidemiology of use of and disparities in caesarean sections. Lancet. 2018;392(10155):1341-8. https://doi.org/10.1016/S0140-6736(18)31928-7.

3. Vogel JP, Betrán AP, Vindevoghel N, Souza JP, Torloni MR, Zhang J, et al. Use of the Robson classification to assess caesarean section trends in 21 countries: a secondary analysis of two WHO multicountry surveys. Lancet Glob Health. 2015;3(5):e260-e70. https://doi.org/10.1016/S2214-109X(1 5)70094-X.

4. Rejno G, Lundholm C, Oberg S, Lichtenstein P, Larsson H, D'Onofrio B, et al. Maternal anxiety, depression and asthma and adverse pregnancy outcomes - a population based study. Sci Rep. 2019;9(1):13101. https://doi.org/10.103 8/s41598-019-49508-Z.

5. Liang J, Mu Y, Li X, Tang W, Wang Y, Liu Z, et al. Relaxation of the one child policy and trends in caesarean section rates and birth outcomes in China between 2012 and 2016: observational study of nearly seven million health facility births. BMJ. 2018;360:k817.

6. Sandall J, Tribe RM, Avery L, Mola G, Visser GHA, Homer CSE, et al. Shortterm and long-term effects of caesarean section on the health of women and children. Lancet. 2018;392(10155):1349-57. https://doi.org/10.1016/S014 0-6736(18)31930-5.

7. Long Q, Kingdon C, Yang F, Renecle MD, Jahanfar S, Bohren MA, et al. Prevalence of and reasons for women's, family members', and health professionals' preferences for cesarean section in China: a mixed-methods systematic review. PLoS Med. 2018;15(10):e1002672. https://doi.org/10.1371/ journal.pmed.1002672.

8. Aune D, Sen A, Henriksen T, Saugstad OD, Tonstad S. Physical activity and the risk of gestational diabetes mellitus: a systematic review and doseresponse meta-analysis of epidemiological studies. Eur J Epidemiol. 2016; 31(10):967-97. https://doi.org/10.1007/s10654-016-0176-0.

9. Takami M, Tsuchida A, Takamori A, Aoki S, Ito M, Kigawa M, et al. Effects of physical activity during pregnancy on preterm delivery and mode of delivery: the Japan environment and Children's study, birth cohort study. PLoS One. 2018;13(10):e0206160. https://doi.org/10.1371/ journal.pone.0206160. 
10. Barakat R, Pelaez M, Cordero Y, Perales M, Lopez C, Coteron J, et al. Exercise during pregnancy protects against hypertension and macrosomia: randomized clinical trial. Am J Obstet Gynecol. 2016;214(5):649.e1-8.

11. Morgan KL, Rahman MA, Hill RA, Zhou SM, Bijlsma G, Khanom A, et al. Physical activity and excess weight in pregnancy have independent and unique effects on delivery and perinatal outcomes. PLoS One. 2014;9(4): e94532. https://doi.org/10.1371/journal.pone.0094532.

12. Di Mascio D, Magro-Malosso ER, Saccone G, Marhefka GD, Berghella V. Exercise during pregnancy in normal-weight women and risk of preterm birth: a systematic review and meta-analysis of randomized controlled trials. Am J Obstet Gynecol. 2016;215(5):561-71. https://doi.org/10.1016/j.ajog.201 6.06 .014 .

13. Davenport MH, Ruchat SM, Sobierajski F, Poitras VJ, Gray CE, Yoo C, et al. Impact of prenatal exercise on maternal harms, labour and delivery outcomes: a systematic review and meta-analysis. Br J Sports Med. 2019; 53(2):99-107. https://doi.org/10.1136/bjsports-2018-099821.

14. Hirshkowitz M, Whiton K, Albert SM, Alessi C, Bruni O, DonCarlos L, et al. National Sleep Foundation's sleep time duration recommendations: methodology and results summary. Sleep Health. 2015;1(1):40-3. https://doi. org/10.1016/j.sleh.2014.12.010.

15. Qiu C, Sanchez SE, Gelaye B, Enquobahrie DA, Ananth CV, Williams MA. Maternal sleep duration and complaints of vital exhaustion during pregnancy is associated with placental abruption. J Matern Fetal Neonatal Med. 2015;28(3):350-5. https://doi.org/10.3109/14767058.2014.916682.

16. Xu YH, Shi L, Bao YP, Chen SJ, Shi J, Zhang RL, et al. Association between sleep duration during pregnancy and gestational diabetes mellitus: a meta-analysis. Sleep Med. 2018;52:67-74. https://doi.org/10.1 016/j.sleep.2018.07.021.

17. Williams MA, Miller RS, Qiu C, Cripe SM, Gelaye B, Enquobahrie D. Associations of early pregnancy sleep duration with trimester-specific blood pressures and hypertensive disorders in pregnancy. Sleep. 2010;33(10):136371. https://doi.org/10.1093/sleep/33.10.1363.

18. Teong ACA, Diong AX, Omar SZ, Tan PC. The impact of self-reported sleep on caesarean delivery in women undergoing induction of labour: a prospective study. Sci Rep. 2017;7(1):12339. https://doi.org/10.1038/s41598017-12410-7.

19. Chang JJ, Pien GW, Duntley SP, Macones GA. Sleep deprivation during pregnancy and maternal and fetal outcomes: is there a relationship? Sleep Med Rev. 2010;14(2):107-14. https://doi.org/10.1016/j.smrv.2009.05.001.

20. Plancoulaine S, Flori S, Bat-Pitault F, Patural H, Lin JS, Franco P. Sleep trajectories among pregnant women and the impact on outcomes: a population-based cohort study. Matern Child Health J. 2017;21(5):1139-46. https://doi.org/10.1007/s10995-016-2212-9

21. Paine SJ, Signal TL, Sweeney B, Priston M, Muller D, Smith A, et al. Maternal sleep disturbances in late pregnancy and the association with emergency caesarean section: a prospective cohort study. Sleep Health. 2020;6(1):65-70. https://doi.org/10.1016/j.sleh.2019.11.004.

22. Li R, Zhang J, Zhou R, Liu J, Dai Z, Liu D, et al. Sleep disturbances during pregnancy are associated with cesarean delivery and preterm birth. J Matern Fetal Neonatal Med. 2017;30(6):733-8. https://doi.org/10.1080/14 767058.2016 .1183637$.

23. Sharma SK, Nehra A, Sinha S, Soneja M, Sunesh K, Sreenivas V, et al. Sleep disorders in pregnancy and their association with pregnancy outcomes: a prospective observational study. Sleep Breath. 2016;20(1):87-93. https://doi. org/10.1007/s11325-015-1188-9.

24. Wang H, Leng J, Li W, Wang L, Zhang C, Li W, et al. Sleep duration and quality, and risk of gestational diabetes mellitus in pregnant Chinese women. Diabet Med. 2017;34(1):44-50. https://doi.org/10.1111/dme.13155.

25. Leng J, Liu G, Zhang C, Xin S, Chen F, Li B, et al. Physical activity, sedentary behaviors and risk of gestational diabetes mellitus: a population-based cross-sectional study in Tianjin, China. Eur J Endocrinol. 2016;174(6):763-73. https://doi.org/10.1530/EJE-15-1103.

26. Hawkins M, Marcus B, Pekow P, Rosal MC, Tucker KL, Spencer RMC, et al. Physical activity and sleep quality and duration during pregnancy among Hispanic women: Estudio PARTO. Behav Sleep Med. 2019;17(6):804-17. https://doi.org/10.1080/15402002.2018.1518225.

27. Chennaoui M, Arnal PJ, Sauvet F, Leger D. Sleep and exercise: a reciprocal issue? Sleep Med Rev. 2015;20:59-72. https://doi.org/10.1016/j.smrv.2014.06.008.

28. Yang X, Hsu-Hage B, Zhang H, Yu L, Dong L, Li J, et al. Gestational diabetes mellitus in women of single gravidity in Tianjin City, China. Diabetes Care. 2002;25(5):847-51. https://doi.org/10.2337/diacare.25.5.847.
29. Yang W, Liu J, Li J, Liu J, Liu H, Wang Y, et al. Interactive effects of prepregnancy overweight and gestational diabetes on macrosomia and large for gestational age: a population-based prospective cohort in Tianjin, China. Diabetes Res Clin Pract. 2019;154:82-9. https://doi.org/10.1016/j.dia bres.2019.06.014.

30. Zhang C, Li Y, Wang L, Sun S, Liu G, Leng J, et al. Blood group AB is protective factor for gestational diabetes mellitus: a prospective populationbased study in Tianjin, China. Diabetes/Metabolism Res Rev. 2015;31(6):62737. https://doi.org/10.1002/dmrr.2650.

31. Leng J, Shao P, Zhang C, Tian H, Zhang F, Zhang S, et al. Prevalence of gestational diabetes mellitus and its risk factors in Chinese pregnant women: a prospective population-based study in Tianjin, China. PLoS One. 2015;10(3):e0121029. https://doi.org/10.1371/journal. pone.0121029.

32. Metzger BE, Gabbe SG, Persson B, Buchanan TA, Catalano PA, Damm P, et al. International association of diabetes and pregnancy study groups recommendations on the diagnosis and classification of hyperglycemia in pregnancy. Diabetes Care. 2010;33(3):676-82.

33. $\mathrm{Hu} G$, Lindström J, Valle $\Pi$, Eriksson JG, Jousilahti $P$, Silventoinen $K$, et al. Physical activity, body mass index, and risk of type 2 diabetes in patients with normal or impaired glucose regulation. Arch Intern Med. 2004;164(8): 892-6. https://doi.org/10.1001/archinte.164.8.892.

34. Sallis JF, Haskell WL, Wood PD, Fortmann SP, Rogers T, Blair SN, et al. Physical activity assessment methodology in the Five-City project. Am J Epidemiol. 1985;121(1):91-106. https://doi.org/10.1093/oxfordjournals.a je.a113987.

35. Buysse DJ, Reynolds CF 3rd, Monk TH, Berman SR, Kupfer DJ. The Pittsburgh sleep quality index: a new instrument for psychiatric practice and research. Psychiatry Res. 1989;28(2):193-213. https://doi.org/10.1016/0165-1781 (89)90047-4.

36. Andersson T, Alfredsson L, Källberg H, Zdravkovic S, Ahlbom A. Calculating measures of biological interaction. Eur J Epidemiol. 2005;20(7):575-9. https:// doi.org/10.1007/s10654-005-7835-x.

37. Baena-Garcia L, Ocon-Hernandez O, Acosta-Manzano P, Coll-Risco I, BorgesCosic M, Romero-Gallardo L, et al. Association of sedentary time and physical activity during pregnancy with maternal and neonatal birth outcomes. The GESTAFIT project. Scand J Med Sci Sports. 2019;29(3):407-14. https://doi.org/10.1111/sms.13337.

38. Hoffmann J, Gunther J, Geyer K, Stecher L, Kunath J, Meyer D, et al. Associations between Prenatal Physical Activity and Neonatal and Obstetric Outcomes-A Secondary Analysis of the Cluster-Randomized Gelis Trial. J Clin Med. 2019;8:10.

39. Owe KM, Nystad W, Stigum H, Vangen S, Bo K. Exercise during pregnancy and risk of cesarean delivery in nulliparous women: a large populationbased cohort study. Am J Obstet Gynecol. 2016;215(6):791 e1-e13.

40. Lee KA, Gay CL. Sleep in late pregnancy predicts length of labor and type of delivery. Am J Obstet Gynecol. 2004;191(6):2041-6. https://doi.org/10.101 6/j.ajog.2004.05.086.

41. Lu Q, Zhang X, Wang Y, Li J, Xu Y, Song X, et al. Sleep disturbances during pregnancy and adverse maternal and fetal outcomes: a systematic review and meta-analysis. Sleep Med Rev. 2021;58:101436. https://doi.org/10.1016/j. smrv.2021.101436

42. Won $\mathrm{CH}$. Sleeping for two: the great paradox of sleep in pregnancy. J Clin Sleep Med. 2015;11(6):593-4. https://doi.org/10.5664/jcsm.4760.

43. Cronin RS, Wilson J, Gordon A, Li M, Culling VM, Raynes-Greenow CH, et al. Associations between symptoms of sleep-disordered breathing and maternal sleep patterns with late stillbirth: findings from an individual participant data meta-analysis. PLoS One. 2020;15(3):e0230861. https://doi. org/10.1371/journal.pone.0230861.

44. Wang $L$, Jin F. Association between maternal sleep duration and quality, and the risk of preterm birth: a systematic review and meta-analysis of observational studies. BMC Pregnancy Childbirth. 2020;20(1):125. https://doi. org/10.1186/s12884-020-2814-5.

45. Masuzaki H, Ogawa Y, Sagawa N, Hosoda K, Matsumoto T, Mise H, et al. Nonadipose tissue production of leptin: leptin as a novel placenta-derived hormone in humans. Nat Med. 1997;3(9):1029-33. https://doi.org/10.1038/ nm0997-1029.

46. Toth B, Fischl A, Scholz C, Kuhn C, Friese K, Karamouti M, et al. Insulin and leptin receptors as possible new candidates for endocrine control in normal and disturbed human pregnancy. Mol Hum Reprod. 2009;15(4):231-9. https://doi.org/10.1093/molehr/gap014. 
47. Ning Y, Williams MA, Butler CL, Muy-Rivera M, Frederick IO, Sorensen TK. Maternal recreational physical activity is associated with plasma leptin concentrations in early pregnancy. Hum Reprod. 2005;20(2):382-9. https:// doi.org/10.1093/humrep/deh615.

48. Qiu C, Frederick IO, Sorensen TK, Enquobahrie DA, Williams MA. Sleep duration and plasma leptin concentrations in early pregnancy among lean and overweight/obese women: a cross sectional study. BMC Res Notes. 2014;7(1):20. https://doi.org/10.1186/1756-0500-7-20.

49. Leijnse JEW, de Heus R, de Jager W, Rodenburg W, Peeters LLH, Franx A et al. First trimester placental vascularization and angiogenetic factors are associated with adverse pregnancy outcome. Pregnancy Hypertens. 2018;13: 87-94. https://doi.org/10.1016/j.preghy.2018.04.008.

50. Xia X, Zhou Z, Shen S, Lu J, Zhang L, Huang P, et al. Effect of a two-stage intervention package on the cesarean section rate in Guangzhou, China: a before-and-after study. PLoS Med. 2019;16(7):e1002846. https://doi.org/10.13 71/journal.pmed.1002846.

51. Yang X, Hsu-Hage B, Zhang H, Zhang C, Zhang Y, Zhang C. Women with impaired glucose tolerance during pregnancy have significantly poor pregnancy outcomes. Diabetes Care. 2002;25(9):1619-24. https://doi.org/1 0.2337/diacare.25.9.1619.

52. Li HT, Luo S, Trasande L, Hellerstein S, Kang C, Li JX, et al. Geographic variations and temporal trends in cesarean delivery rates in China, 20082014. JAMA. 2017;317(1):69-76. https://doi.org/10.1001/jama.2016.18663.

\section{Publisher's Note}

Springer Nature remains neutral with regard to jurisdictional claims in published maps and institutional affiliations.

Ready to submit your research? Choose BMC and benefit from:

- fast, convenient online submission

- thorough peer review by experienced researchers in your field

- rapid publication on acceptance

- support for research data, including large and complex data types

- gold Open Access which fosters wider collaboration and increased citations

- maximum visibility for your research: over $100 \mathrm{M}$ website views per year

At BMC, research is always in progress.

Learn more biomedcentral.com/submissions 